\title{
Restoration of shoulder motion using single- versus dual-nerve repair in obstetrical brachial plexus injury
}

\author{
Alain Joe Azzi, MD, ${ }^{1}$ Hassan AINaeem, MD, ${ }^{1}$ Camille Aubin-Lemay, MD, ${ }^{1}$ \\ Julie Chakriya Kvann, MD, ${ }^{1}$ Peter Alam, MD, ${ }^{1}$ Helene Retrouvey, MD, ${ }^{2}$ \\ Salah Aldekhayel, MD, FRCSC, ${ }^{1}$ and Teanoosh Zadeh, MD, FRCSC ${ }^{1}$

\begin{abstract}
'Division of Plastic \& Reconstructive Surgery, Royal Victoria Hospital, McGill University, Montreal, Quebec; and 2Division of Plastic \& Reconstructive Surgery, Toronto General Hospital, Toronto, Ontario, Canada
\end{abstract}

\begin{abstract}
OBJECTIVE The purpose of this study was to compare shoulder abduction and external rotation (ER) after single-nerve repair of the upper trunk alone versus dual-nerve repair of both the upper trunk and the suprascapular nerve.

METHODS A retrospective chart review of a single surgeon's experience repairing obstetrical brachial plexus injuries between June 1995 and June 2015 was performed. Eight patients underwent repair of the upper trunk alone, and 10 patients underwent repair of the upper trunk and the suprascapular nerve. Shoulder abduction and ER ranges of motion (ROMs) (in degrees) were recorded preoperatively and postoperatively. Postoperative ROM and the difference in ROM gained after surgery were compared by independent t-test analysis.
\end{abstract}

RESULTS The mean follow-up time was 161.4 weeks (range 62-514 weeks, SD 124.0 weeks). The mean patient age at the time of surgery was 31.3 weeks (range 19.9-47.0 weeks, SD 6.9 weeks). The mean postoperative shoulder abduc-

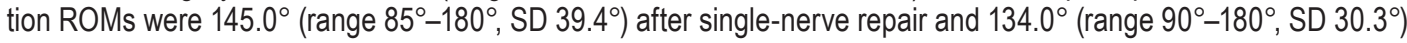
after dual-nerve repair $(p=0.51)$. The mean postoperative shoulder ER ROMs were $67.5^{\circ}$ (range $10^{\circ}-95^{\circ}, S^{\circ} 28.8^{\circ}$ ) after single-nerve repair and $72.0^{\circ}$ (range $10^{\circ}-95^{\circ}$, SD $31.3^{\circ}$ ) after dual-nerve repair $(p=0.76)$.

CONCLUSIONS The authors found no difference in shoulder abduction and ER between patients who underwent single-nerve repair of the upper trunk alone and those who underwent dual-nerve repair of both the upper trunk and the suprascapular nerve.

https://thejns.org/doi/abs/10.3171/2017.11.PEDS17493

KEY WORDS obstetrical brachial plexus injury; Erb's palsy; neurotization; nerve transfer; nerve graft; peripheral nerve

I ${ }_{\mathrm{T}}$ is widely accepted that abduction and external rotation (ER) are crucial for shoulder function restoration after obstetrical brachial plexus injuries (OBPIs). Various approaches and techniques for restoring shoulder function have been described in the literature. Adequate results from many types of repairs have been reported in the literature. Common donors for nerve transfer include the spinal accessory nerve, intercostal nerves, and long head of the triceps motor branch., ${ }^{1,8-11,17}$ Common recipients include, but are not limited to, the suprascapular nerve, the upper trunk, and the axillary nerve. ${ }^{15,16,19}$ Double- and triple-nerve transfers also have been widely used with various combinations of recipients and donors with or without nerve grafts..$^{2-4,6}$ In this study, we investigated the results of shoulder abduction and ER in patients after single-nerve repair of the upper trunk versus those in patients after dual-nerve repair of the upper trunk and the suprascapular nerve.

\section{Methods}

After obtaining approval from the McGill University Health Center Research Ethics Board, we reviewed the cases of patients with OBPIs managed by the senior author (T.Z.) between June 1995 and June 2015. Patients in the single-nerve-repair group (group 1) were included if

ABBREVIATIONS ER = external rotation; OBPI = obstetrical brachial plexus injury; ROM = range of motion.

SUBMITTED August 31, 2017. ACCEPTED November 7, 2017.

INCLUDE WHEN CITING Published online February 23, 2018; DOI: 10.3171/2017.11.PEDS17493. 
TABLE 1. Patient characteristic comparison

\begin{tabular}{lccc}
\hline \multicolumn{1}{c}{ Characteristic } & Single-Nerve Repair & Dual-Nerve Repair & $p$ Value \\
\hline Total no. of patients & 8 & 10 & 0.63 \\
\hline Mean follow-up time in wks (range, SD) & $144.8(62.0-514.0,155.9)$ & $174.6(89.0-384.0,98.5)$ & 0.18 \\
\hline Sex, male (\%) & 62.5 & 30.0 & 0.24 \\
\hline Mean gestational age in wks (range, SD) & $39.4(38.7-41.0,0.77)$ & $39.9(38.9-40.9,0.76)$ & 0.69 \\
\hline Mean birth weight in g (range, SD) & $4403.0(3570.0-5060.0,470.8)$ & $4301.5(3429.9-5669.6,565.0)$ & 0.41 \\
\hline Maternal diabetes (\%) & 25.0 & 10.0 & 0.68 \\
\hline Assisted delivery (\%) & 87.5 & 80.0 & 0.41 \\
\hline Shoulder dystocia (\%) & 75.0 & 90.0 & 0.37 \\
\hline Clavicular fracture (\%) & 0 & 10.0 & \\
\hline Humeral fracture (\%) & 0 & 0 & 0.19 \\
\hline Asphyxia (\%) & 0 & 20.0 & \\
\hline
\end{tabular}

they underwent interpositional nerve grafting of the upper trunk. All interpositional nerve grafts were performed with a sural nerve donor. Patients were included in the dual-nerve-repair group (group 2) if they underwent additional neurotization of the suprascapular nerve with the spinal accessory nerve. Patients were included if their injury was classified as Narakas ${ }^{12,13}$ grade 1 (C5-6 injury) or 2 (C5-7 injury). Each patient underwent primary brachial plexus nerve reconstruction. Patients were excluded from the study if their injury included lower trunk involvement (C8-T1), they were followed up for $<12$ months, or they underwent one or more secondary procedures.

The surgeon's decision for considering surgery for a patient with OBPI is based on the following principles: 1) no recovery of biceps function at 3 months of age, 2) inadequate recovery of biceps function at 5-9 months of age, or 3) Horner syndrome in association with total palsy or involvement of C8-T1 at 3 months of age. The general goals of surgery are to maximize shoulder abduction and ER and to maximize elbow flexion if there is significant preoperative deficit. Each patient in this study underwent a supraclavicular exploration of the brachial plexus and, if necessary, infraclavicular exploration via an anterior approach. Target distal nerves for shoulder function were the posterior division of the upper trunk (group 1) with or without the addition of the suprascapular nerve (group 2). All nerve repairs were performed with an end-to-side coaptation (nerve grafts and nerve transfers) according to surgeon preference. The window for all end-to-side coaptations involved both an epineural and a perineural partial transection of nerve fibers ("lesional window"). Distal coaptation of sural nerve grafts to the posterior division of the upper trunk was performed for abduction of the shoulder (axillary nerve). Proximal coaptations to the chosen viable nerve root (C-5, C-6, or C-7) were performed. The distal coaptation site of the spinal accessory nerve transfer was the suprascapular nerve. The site of distal coaptations for the nerve grafts and nerve transfers was chosen based on the maximal response from direct intraoperative nerve stimulation (the point of maximal muscular contraction). All coaptations were performed under a microscope using a combination of 10-0 Ethilon sutures and Tisseel fibrin sealant.
All patients were followed in a multidisciplinary OBPI clinic. Data were collected from electronic and paper medical records by 2 independent reviewers. Abduction range of motion (ROM) was measured (in degrees) against gravity. The hand on the abdomen was considered 0 degrees when measuring ER ROM with gravity eliminated. Preoperative and postoperative shoulder abduction and ER ROMs were measured by the occupational therapist and the physical therapist in the OBPI clinic. In the event of a discrepancy between measurements made by the occupational and physical therapists, the larger value was kept. Means and frequencies were calculated for continuous variables and categorical data, respectively. Postoperative $\mathrm{ROM}$ and the difference in ROM gained (in degrees) after surgery were compared by independent t-test analysis. Statistical significance was set at a $p$ value of 0.05 . All analyses were carried out using the statistical program IBM SPSS (IBM Corp.).

\section{Results}

A total of 18 patients were included in this study. The mean follow-up time was 161.4 weeks (range 62-514 weeks, SD 124.0 weeks). The mean patient age at the time of surgery was 31.3 weeks (range 19.9-47.0 weeks, SD 6.9 weeks). The mean birth weight was $4347 \mathrm{~g}$ (range 3429$5669 \mathrm{~g}$, SD $513 \mathrm{~g}$ ), and the mean gestational age was 39.7 weeks (range 38.7-41.0 weeks, SD 0.78 weeks). Patient characteristics of both groups are compared in Table 1 . The mean postoperative shoulder abduction ROMs were $145.0^{\circ}$ (range $85^{\circ}-180^{\circ}, \mathrm{SD} 39.4^{\circ}$ ) after single-nerve repair and $134.0^{\circ}$ (range $90^{\circ}-180^{\circ}$, SD $30.3^{\circ}$ ) after dual-nerve repair. The mean postoperative abduction ROMs gained were $83.2^{\circ}$ (range $15^{\circ}-180^{\circ}, \mathrm{SD} 63.7^{\circ}$ ) after single-nerve repair and $89.0^{\circ}$ (range $20^{\circ}-150^{\circ}$, SD $38.9^{\circ}$ ) after dualnerve repair. The mean postoperative shoulder ER ROMs were $67.5^{\circ}$ (range $10^{\circ}-95^{\circ}, \mathrm{SD} 28.8^{\circ}$ ) after single-nerve repair and $72.0^{\circ}$ (range $10^{\circ}-95^{\circ}, \mathrm{SD} 31.3^{\circ}$ ) after dual-nerve repair. The mean postoperative ER ROMs gained were $53.8^{\circ}$ (range $0^{\circ}-95^{\circ}, \mathrm{SD} 34.3^{\circ}$ ) after single-nerve repair and $69.0^{\circ}$ (range $10^{\circ}-95^{\circ}$, SD $29.7^{\circ}$ ) after dual-nerve repair. We found no statistical difference in postoperative shoulder abduction and ER ROMs between the single- and 
TABLE 2. Data summary for patients who underwent single-nerve repair (upper trunk alone)

\begin{tabular}{|c|c|c|c|c|c|c|c|c|}
\hline \multirow[b]{2}{*}{ Pt No. } & \multirow[b]{2}{*}{ Sex } & \multirow{2}{*}{$\begin{array}{l}\text { Age at Op } \\
\text { (wks) }\end{array}$} & \multirow[b]{2}{*}{ Injury } & \multirow[b]{2}{*}{ Repair } & \multicolumn{2}{|c|}{ Postop ROMs $\left({ }^{\circ}\right)$} & \multicolumn{2}{|c|}{ Changes in $\mathrm{ROM}\left({ }^{\circ}\right)^{*}$} \\
\hline & & & & & Abduction & ER & Abduction & ER \\
\hline 1 & M & 19.9 & C5-6 & C6-UT & 180 & 90 & 180 & 90 \\
\hline 2 & M & 40.7 & C5-7 & C6-UT & 95 & 45 & 15 & 45 \\
\hline 3 & M & 28.9 & C5-6 & C7-UT & 180 & 10 & 180 & 10 \\
\hline 4 & M & 29.7 & C5-7 & C7-UT & 180 & 90 & 70 & 60 \\
\hline 5 & $\mathrm{~F}$ & 32.6 & C5-7 & C7-UT & 160 & 80 & 70 & 0 \\
\hline 6 & M & 36.3 & C5-7 & C7-UT & 120 & 70 & 30 & 70 \\
\hline 7 & $\mathrm{~F}$ & 39.6 & C5-7 & X1-UT, C5-UT, C7-UT & 160 & 95 & 80 & 95 \\
\hline 8 & $\mathrm{~F}$ & 47.0 & C5-7 & C5-UT, C7-UT & 85 & 60 & 40 & 60 \\
\hline
\end{tabular}

$\mathrm{Pt}=$ patient; $\mathrm{UT}=$ upper trunk; $\mathrm{X} 1$ = spinal accessory nerve.

* ROM gained after surgery (postoperative minus preoperative ROM).

dual-nerve-repair groups ( $\mathrm{p}=0.51$ and 0.76 , respectively). We also found no difference between the single- and dualnerve-repair groups for shoulder abduction and ER ROMs gained $(\mathrm{p}=0.81$ and 0.33 , respectively). Data summaries for the patients who underwent single-nerve repair and those who underwent dual-nerve repair are provided in Tables 2 and 3, respectively.

\section{Discussion}

The purpose of this study was to compare restoration of shoulder function after single-nerve repair versus that after dual-nerve repair. Comparing donor nerves was not the purpose of this study. Increasing the number of donor nerves used in such repair procedures has been reported to improve shoulder function in the adult population. Cardenas-Mejia et al. ${ }^{3}$ reported significantly improved shoulder abduction in patients after double- or triple-nerve transfers when compared with that in patients after single-nerve transfer. After pooling data from multiple procedures together, they reported mean shoulder abduction ROMs of $160^{\circ}$ after triple-nerve transfer, $85^{\circ}$ after double-nerve transfer, and $65^{\circ}$ after single-nerve transfer. Garg et al. ${ }^{7}$ performed a systematic review of the literature and reported improved shoulder abduction and ER in patients after dual-nerve transfer ( 2 donors and 2 recipients) over that in patients after single-nerve transfer (1 recipient) to treat traumatic brachial plexus injury.

Comparing nerve grafting and neurotization was also not the purpose of this study. Conflicting evidence exists with regard to superiority of one method over the other for shoulder function restoration in both the adult and pediatric populations. In a systematic review of traumatic brachial plexus injuries, Garg et al. ${ }^{7}$ found no significant difference in shoulder abduction of grade M4 or greater (according to the British Medical Research Council grading system) when comparing neurotization versus nerve grafting to the axillary nerve. Another study by Baltzer et al. ${ }^{1}$ also found no difference in shoulder abduction ROMs between adults who underwent nerve transfer and those who underwent nerve grafting to the axillary nerve. Terzis and $\mathrm{Kostas}^{17}$ found significantly greater shoulder abduction ROMs after direct transfer of the spinal accessory nerve to the suprascapular nerve compared with that after a nerve graft interposed between the 2 nerves $\left(57.7^{\circ}\right.$ vs $44.5^{\circ}$, respectively, $\left.\mathrm{p}<0.05\right)$. In a large comparative

TABLE 3. Data summary for patients who underwent dual-nerve repair (upper trunk and suprascapular nerve)

\begin{tabular}{|c|c|c|c|c|c|c|c|c|}
\hline \multirow{2}{*}{$\begin{array}{l}\mathrm{Pt} \\
\text { No. }\end{array}$} & \multirow[b]{2}{*}{ Sex } & \multirow{2}{*}{$\begin{array}{c}\text { Age at Op } \\
\text { (wks) }\end{array}$} & \multirow[b]{2}{*}{ Injury } & \multirow[b]{2}{*}{ Repair } & \multicolumn{2}{|c|}{ Postop ROMs $\left({ }^{\circ}\right)$} & \multicolumn{2}{|c|}{ Changes in $\mathrm{ROM}\left({ }^{\circ}\right)^{\star}$} \\
\hline & & & & & Abduction & $\mathrm{ER}$ & Abduction & ER \\
\hline 9 & $\mathrm{~F}$ & 28.9 & C5-6 & X1-SSN, C6-UT, C7-UT & 180 & 90 & 120 & 80 \\
\hline 10 & $\mathrm{~F}$ & 29.1 & C5-7 & X1-SSN, C5-UT & 150 & 95 & 150 & 95 \\
\hline 11 & $\mathrm{~F}$ & 30.0 & C5-6 & X1-SSN, C5-UT & 100 & 90 & 60 & 80 \\
\hline 12 & M & 28.3 & C5-6 & X1-SSN, C6-SSN, C5-UT, C6-UT & 120 & 45 & 90 & 45 \\
\hline 13 & M & 39.7 & C5-6 & X1-SSN, C7-UT & 90 & 10 & 45 & 10 \\
\hline 14 & $\mathrm{~F}$ & 29.9 & C5-7 & X1-SSN, C5-SSN, C5-UT & 170 & 90 & 125 & 90 \\
\hline 15 & M & 23.1 & C5-7 & X1-SSN, C5-UT & 110 & 30 & 20 & 30 \\
\hline 16 & $\mathrm{~F}$ & 25.1 & C5-6 & X1-SSN, C5-UT, C7-UT & 150 & 90 & 90 & 80 \\
\hline 17 & $\mathrm{~F}$ & 25.4 & C5-7 & X1-SSN, C7-UT & 150 & 90 & 100 & 90 \\
\hline 18 & M & 29.0 & C5-7 & X1-SSN, C7-UT & 120 & 90 & 90 & 90 \\
\hline
\end{tabular}

$\mathrm{SSN}=$ suprascapular nerve.

* ROM gained after surgery (postoperative minus preoperative ROM). 
study of children with OBPI, Tse et al. ${ }^{18}$ found no statistical difference in ER ROMs between patients who underwent spinal accessory nerve transfer to the suprascapular nerve and patients who underwent nerve grafting from the proximal C-5 stump. A retrospective study on OBPIs by Seruya et al. compared spinal accessory nerve transfer versus sural nerve grafts for suprascapular nerve repair. ${ }^{14}$ They reported a higher median composite Mallet score in their nerve-transfer group (compared to their nerve-graft group) 5 years after surgery; however, the difference did not reach statistical significance (16.0 vs 13.0 , respectively, $\mathrm{p}=0.07$ ).

We hypothesized that the addition of a nerve transfer in this study's dual-nerve-repair group might result in greater shoulder function. We found no difference in shoulder $a b-$ duction and ER ROMs between patients who underwent single-nerve repair of the upper trunk alone and those who underwent dual-nerve repair of both the upper trunk and the suprascapular nerve. We were unable to find a similar study in the pediatric literature for comparison. Chuang et al. ${ }^{5}$ reported their shoulder abduction results after various nerve-transfer combinations after a minimum of 2 years' follow-up. Their patients' ages ranged from 8 months to 47 years. They reported abduction ROMs after dual-nerve repair of both the suprascapular and axillary nerves that were greater than those after single-nerve repair of the axillary nerve or the suprascapular nerve alone. The mean shoulder abduction ROM after dual-nerve repair was $55^{\circ}$, compared with $<20^{\circ}$ after single-nerve repair. They concluded that dual-nerve neurotization provides good shoulder ROM and that neurotization of C-5 is also effective, because it provides axons to the suprascapular and axillary nerves. However, they did not perform nerve repair of C-5 alone to compare with the other surgeries or support their statement. ${ }^{5}$ Terzis and Kosta ${ }^{17}$ also found that dual-nerve repair of the suprascapular and axillary nerves yielded improved shoulder results over those with repair of the suprascapular nerve alone; however, their results were not statistically significant.

We acknowledge that our results are subject to the forms of bias associated with retrospective reviews. Although the purpose of our study was to compare functional restoration after single-nerve repair versus that after dualnerve repair, a potential confounding factor that could not be controlled for is the number of donor nerves involved in the repair. Most repairs involved a single-cable graft; however, dual or even triple grafts were used for more severe injuries, which could represent an example of potential selection bias. Shoulder outcome might be affected by surgical technique (nerve transfer vs nerve graft), which is a variable that could not be accounted for because of the paucity of relevant patients. Potential confounding factors such as frequency, intensity, and compliance with physical/occupational therapy were not accounted for. We also recognize that it is difficult to extrapolate results from a single-center experience. Proof of generalizability of our findings will require external validation by other investigators, preferably with standardized scales of outcome, such as the British Medical Research Council scale. We also acknowledge that our study was underpowered, and larger prospective studies will be required to confirm our findings.

\section{Conclusions}

By targeting a single nerve, surgeons have more flexibility and options in treating complex OBPIs with multiple avulsions/ruptures. More options are available for concomitant elbow or hand function repair, which can improve the overall results of the involved upper extremity. Dual-nerve repair of the upper trunk and the suprascapular nerve offers no further benefit than single-nerve repair of the upper trunk alone for shoulder function restoration after OBPIs.

\section{References}

1. Baltzer HL, Kircher MF, Spinner RJ, Bishop AT, Shin AY: A comparison of outcomes of triceps motor branch-to-axillary nerve transfer or sural nerve interpositional grafting for isolated axillary nerve injury. Plast Reconstr Surg 138:256e264e, 2016

2. Bertelli JA, Ghizoni MF: Nerve root grafting and distal nerve transfers for C5-C6 brachial plexus injuries. J Hand Surg Am 35:769-775, 2010

3. Cardenas-Mejia A, O'Boyle CP, Chen KT, Chuang DC: Evaluation of single-, double-, and triple-nerve transfers for shoulder abduction in 90 patients with supraclavicular brachial plexus injury. Plast Reconstr Surg 122:1470-1478, 2008

4. Chu B, Wang H, Chen L, Gu Y, Hu S: Dual nerve transfers for restoration of shoulder function after brachial plexus avulsion injury. Ann Plast Surg 76:668-673, 2016

5. Chuang DC, Lee GW, Hashem F, Wei FC: Restoration of shoulder abduction by nerve transfer in avulsed brachial plexus injury: evaluation of 99 patients with various nerve transfers. Plast Reconstr Surg 96:122-128, 1995

6. Estrella EP, Mella PM: Double nerve transfer for elbow flexion in obstetric brachial plexus injury: a case report. J Plast Reconstr Aesthet Surg 66:423-426, 2013

7. Garg R, Merrell GA, Hillstrom HJ, Wolfe SW: Comparison of nerve transfers and nerve grafting for traumatic upper plexus palsy: a systematic review and analysis. J Bone Joint Surg Am 93:819-829, 2011

8. Ghanghurde BA, Mehta R, Ladkat KM, Raut BB, Thatte MR: Distal transfers as a primary treatment in obstetric brachial plexus palsy: a series of 20 cases. J Hand Surg Eur Vol 41:875-881, 2016

9. Grossman JA, Di Taranto P, Alfonso D, Ramos LE, Price AE: Shoulder function following partial spinal accessory nerve transfer for brachial plexus birth injury. J Plast Reconstr Aesthet Surg 59:373-375, 2006

10. Ladak A, Morhart M, O'Grady K, Wong JN, Chan KM, Watt MJ, et al: Distal nerve transfers are effective in treating patients with upper trunk obstetrical brachial plexus injuries: an early experience. Plast Reconstr Surg 132:985e-992e, 2013

11. Merrell GA, Barrie KA, Katz DL, Wolfe SW: Results of nerve transfer techniques for restoration of shoulder and elbow function in the context of a meta-analysis of the English literature. J Hand Surg Am 26:303-314, 2001

12. Narakas AO: Obstetric brachial plexus injuries, in Lamb DW (ed): The Paralysed Hand. Edinburgh: Churchill Livingstone, 1987, pp 116-135

13. Narakas AO, Hentz VR: Neurotization in brachial plexus injuries: indication and results. Clin Orthop Relat Res 237:43-56, 1998

14. Seruya M, Shen SH, Fuzzard S, Coombs CJ, McCombe DB, Johnstone BR: Spinal accessory nerve transfer outperforms cervical root grafting for suprascapular nerve reconstruction in neonatal brachial plexus palsy. Plast Reconstr Surg 135:1431-1438, 2015 
15. Terzis JK, Kokkalis ZT: Shoulder function following primary axillary nerve reconstruction in obstetrical brachial plexus patients. Plast Reconstr Surg 122:1457-1469, 2008

16. Terzis JK, Kostas I: Outcomes with suprascapular nerve reconstruction in obstetrical brachial plexus patients. Plast Reconstr Surg 121:1267-1278, 2008

17. Terzis JK, Kostas I: Suprascapular nerve reconstruction in 118 cases of adult posttraumatic brachial plexus. Plast Reconstr Surg 117:613-629, 2006

18. Tse R, Marcus JR, Curtis CG, Dupuis A, Clarke HM: Suprascapular nerve reconstruction in obstetrical brachial plexus palsy: spinal accessory nerve transfer versus C5 root grafting. Plast Reconstr Surg 127:2391-2396, 2011

19. van Ouwerkerk WJ, Uitdehaag BM, Strijers RL, Frans N, Holl K, Fellner FA, et al: Accessory nerve to suprascapular nerve transfer to restore shoulder exorotation in otherwise spontaneously recovered obstetric brachial plexus lesions. Neurosurgery 59:858-869, 2006

\section{Disclosures}

The authors report no conflict of interest concerning the materials or methods used in this study or the findings specified in this paper.

\section{Author Contributions}

Conception and design: Azzi, AlNaeem, Kvann, Alam, Zadeh. Acquisition of data: Azzi, AlNaeem, Kvann, Alam, Retrouvey, Aldekhayel. Analysis and interpretation of data: Azzi, AlNaeem, Aubin-Lemay, Zadeh. Drafting the article: Azzi, AlNaeem,

Aubin-Lemay, Kvann, Zadeh. Critically revising the article: Azzi, Aubin-Lemay. Reviewed submitted version of manuscript: Azzi, Alam, Zadeh. Approved the final version of the manuscript on behalf of all authors: Azzi. Statistical analysis: Azzi. Administrative/technical/material support: Alam, Retrouvey, Aldekhayel. Study supervision: Zadeh.

\section{Supplementary Information}

Previous Presentations

Portions of this paper were presented in abstract form at the Fraser Gurd Surgical Research Forum held in Montreal, QC, Canada, on May 26, 2016; the H. Bruce Williams Pediatric Surgical Research Day held in Montreal, QC, Canada, on June 15, 2016; and the American Society for Surgery of the Hand Annual Meeting held in San Francisco, CA, on September 8, 2017.

\section{Correspondence}

Alain Joe Azzi: Montreal General Hospital, Montreal, QC, Canada. alain.azzi@mail.mcgill.ca. 